Etnográfica

Revista do Centro em Rede de Investigação em

Antropologia

vol. 21 (3) | 2017

Vol. 21 (3)

\title{
O Parque Natural do Fogo: cosmologias e territorialidades
}

Fogo Natural Park (Cape Verde): cosmology and territoriality

Flávia Lenira Gomes Marques dos Santos

\section{(2) OpenEdition}

Journals

Edição electrónica

URL: https://journals.openedition.org/etnografica/5005

DOI: 10.4000/etnografica.5005

ISSN: 2182-2891

\section{Editora}

Centro em Rede de Investigação em Antropologia

\section{Edição impressa}

Data de publição: 1 outubro 2017

Paginação: 509-525

ISSN: 0873-6561

\section{Refêrencia eletrónica}

Flávia Lenira Gomes Marques dos Santos, «O Parque Natural do Fogo: cosmologias e

territorialidades», Etnográfica [Online], vol. 21 (3) | 2017, posto online no dia 24 março 2018, consultado

o 11 fevereiro 2022. URL: http://journals.openedition.org/etnografica/5005 ; DOI: https://doi.org/

10.4000/etnografica.5005

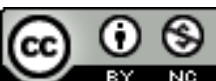

Etnográfica is licensed under a Creative Commons Attribution-NonCommercial 4.0 International License. 


\section{O Parque Natural do Fogo: cosmologias e territorialidades}

\section{Flávia Lenira Gomes Marques dos Santos}

O artigo apresenta uma pesquisa sobre o Parque Natural do Fogo, na ilha do Fogo, em Cabo Verde, tendo como foco as sociocosmologias caldeirenses. A pesquisa etnográfica foi realizada em Chã das Caldeiras, na qual explorei alguns contextos cosmopolitas onde o cosmos e a política não estão isolados. A criação do referido parque foi mediada por um conjunto de conceções tecnocientíficas e burocracias administrativas que se detêm apenas nos riscos e "recursos" e que bloqueiam a relação ontológica singularizante do caldeirense com o cosmos. Após análise dos dados levantados, constatei que tanto o vulcão como as plantas, animais e outras entidades não são percebidos pelos caldeirenses como elementos distantes deles, mas, pelo contrário, como elementos que com eles se relacionam. Há uma grande relação entre seres humanos e não humanos que não foi levada em conta aquando da implementação do referido parque, o que pode levar ao fracasso de algumas medidas e ações que vêm sendo implementadas.

PALAVRAS-CHAVE: parque natural, natureza-cultura, Chã das Caldeiras, caldeirense, cosmologias.

Fogo Natural Park (Cape Verde): cosmology and territoriality - The article presents a research on the Natural Park of Fogo Island, Cape Verde, focusing on the socio-cosmologies from Chã das Caldeiras, where the ethnographic research was performed exploring some cosmopolitan contexts in which the cosmos and politics are not isolated. The creation of that park was mediated by a set of techno-scientific conceptions and administrative bureaucracy that considered only the risks and "resources", blocking the singling ontological relationship of the caldeirense with the cosmos. The analysis of the data showed that the volcano, the plants, animals and other entities are not perceived by the people from Chã das Caldeiras as distant elements, but rather as elements that they relate to. There is a strong relationship between humans and non-humans that was not taken into account when implementing the natural park, which can lead to the failure of some measures and actions being implemented.

KEYWORDS: Natural Park, nature-culture, Chã das Caldeiras, caldeirense, cosmologies.

SANTOS, Flávia Lenira Gomes Marques dos (fa7santos@hotmail.com) - Universidade de Cabo Verde (UniCV), Cabo Verde. 


\section{INTRODUÇÃO}

No período de 2010 a 2014 desenvolvi uma pesquisa de campo etnográfica na região de Chã das Caldeiras, na ilha do Fogo, em Cabo Verde, com o intuito de entender as sociocosmologias caldeirenses, tendo explorado alguns contextos cosmopolíticos onde o cosmos e a política não estão isolados. ${ }^{1} \mathrm{Ou}$ seja, foquei a pesquisa em situações de convivência ou embate entre práticas e discursos "ocidentais-modernos" e a "cosmologia caldeirense", ${ }^{2}$ que me permitiram questionar a colonialidade do nosso pensamento e desconstruir discursos e práticas hegemónicas, tendo como inquietação os limites da participação, nomeadamente outros modos de estar e ser da modernidade que não aqueles da construção de parques em sociedades africanas.

Naquela região, a definição do Parque Natural do Fogo foi mediada por um conjunto de conceções tecnocientíficas e burocracias administrativas que se detêm apenas nos riscos e "recursos" e que bloqueiam a relação ontológica singularizante do caldeirense com o cosmos, quando muitos desses "recursos" são considerados pela população nativa como entes sociais, dotados de subjetividade, agência e cultura.

Chã das Caldeiras ${ }^{3}$ é a única área habitada no perímetro do parque e faz parte do município de Santa Catarina, com quatro pequenos povoados - Portela, Bangaeira, Cova Tina e Djeu de Lorna - localizados na base do "Vulcão do Fogo". O "Vulcão do Fogo" ou "Pico do Fogo" constitui o cone eruptivo principal da ilha, com um diâmetro basal de cinco quilómetros e uma altitude máxima de $2829 \mathrm{~m}$, cerca de $1200 \mathrm{~m}$ acima do fundo da caldeira.

Chã das Caldeiras tem uma população de 697 habitantes, 340 do sexo masculino e 357 do sexo feminino, ${ }^{4}$ que vivem, essencialmente, da agricultura (fruticultura, horticultura e vinha), sua principal fonte de sobrevivência, e da pecuária (criação de vacas, cabras, porcos, mulas, burros, galinhas).

As pesquisas exploratórias realizadas em Chã das Caldeiras revelaram alguns constrangimentos e resistências locais advenientes da delimitação daquele

l Tratou-se de pesquisa de doutoramento em Ciências Sociais na Universidade de Cabo Verde (UniCV).

2 Não entendo as cosmologias caldeirenses enquanto estruturas rígidas e imutáveis, mas sim enquanto formas de lógica, pensamento, comportamento, ação, ou seja, formas de um outro mundo possível, onde podemos alcançar maneiras diferentes de perceber o corpo ou a pessoa.

3 Chã das Caldeiras é uma região marcada por erupções vulcânicas. Do total de 25 erupções (Ribeiro 1998) de que se tem registo na ilha do Fogo, três ocorreram após o povoamento de Chã das Caldeiras: uma em 12 de junho de 1951 (Ribeiro 1998), outra em 2 de abril de 1995 (Costa 1997) e a última em 23 de novembro de 2014. A erupção de 1951 aconteceu após 94 anos de repouso, a de 1995 após 44 anos e a de 2014 após 19 anos. É de se realçar que esta última erupção aconteceu após o término do trabalho de campo.

4 Segundo dados do Instituto Nacional de Estatística, obtidos no Censo 2010, disponíveis em $<$ http://ine.cv/censo_quadros/fogo-2 $>$. 
parque, que vinham sendo noticiados nos meios de comunicação social desde meados da década de 2000.

Partia do pressuposto de que as expectativas dos caldeirenses e do poder público em relação aos benefícios dessa política pública acabavam divergindo devido à restrição de direitos de uso do território em nome da conservação da "natureza".

À medida que me inseria no campo começava a perceber outras dimensões implícitas a essas resistências. Entre essas dimensões, desde o primeiro trabalho de campo realizado em Chã das Caldeiras, em outubro de 2010, foram-me relatados alguns casos de abalos sísmicos que vinham acontecendo esporadicamente e me causavam temor. Ao questionar os caldeirenses sobre tais abalos sísmicos, diziam-me em conversas informais: "o vulcão é nosso amigo, ele nos avisa quando vai entrar em erupção, ele escolhe o lugar para furar”, demonstrando grande respeito pelo mesmo. Ouvindo tais afirmações, estava entrando num devir outro que desestabilizava meu conhecimento. O devir é aqui entendido segundo a aceção de Deleuze e Guattari (1980): é o movimento através do qual um sujeito sai de sua própria condição por meio de uma relação de afetos que consegue estabelecer com uma condição outra, no sentido em que atinge e modifica um indivíduo, aumentando ou modificando sua potência.

A partir daquela altura começava a perceber que os caldeirenses lidam com entidades de forma diferente da ontologia moderna, o que significa que os vegetais, animais, vulcão e outros seres do cosmos não eram percebidos por eles como elementos distantes, relacionados a uma categoria separada e afastada do humano.

Através de vários depoimentos trazidos para a etnografia, despontam evidências de que atribuem a entidades a que nós chamamos "naturais" uma intencionalidade subjetiva, permitindo o diálogo com os estudos de Descola (2005) entre os ameríndios, pois essas entidades são concebidas e tratadas como pessoas.

"Vulcão é o ator principal de Chã, é nosso presidente. Estamos contentes com ele, porque nos apoia aqui. Tudo o que vês aqui deve-se a este vulcão" [A.T., 92 anos, pensionista, 2012].

Por este enunciado fica assente que o vulcão é a figura central de Chã das Caldeiras, responsável pela promoção da melhoria de vida dos caldeirenses, garantindo-lhes um terreno fértil.

Com base nessas evidências, o desafio que se propõe consiste em pensar as dinâmicas das relações entre os caldeirenses, o vulcão, os animais e as plantas, levando em consideração as inter-relações e interdependências existentes entre os domínios "natureza" e "cultura", de acordo com a abordagem simétrica de Latour (1994). 
A metodologia adotada teve um cariz qualitativo, com recurso a pesquisas bibliográficas e documentais, acompanhamento de noticiários e a realização de uma etnografia na qual pretendi fornecer elementos que explicitassem as sociocosmologias caldeirenses, experimentando outras possibilidades e destacando a multiplicidade de suas especificidades, ao invés de me concentrar em supostas unidades que constituiriam o conjunto.

\section{A IMPORTAÇÃO DO MODELO DE PARQUE NATURAL: TENSÕES COSMO-ONTOLÓGICAS}

Com a independência de Cabo Verde, em 1975, as modalidades de regulação política e social foram favoráveis à importação de vários modelos. Daí que uma independência política não significou uma independência económica, pois o desenvolvimento do país é guiado pela ajuda internacional e investimento externo direto.

A partir da década de 80 começaram a ser importados vários modelos ambientais, de defesa do desenvolvimento durável e da biodiversidade, direcionados para a gestão de "recursos naturais" e a proteção de espaços em África. A política de modelos em África, segundo a reflexão de Darbon (1999), acontece desde a revolução neoliberal do final dos anos 70 , período do movimento de libertação das colónias.

Os anos 90 marcam um momento decisivo na história da gestão dos "recursos naturais", tanto a nível mundial como em Cabo Verde, com uma explosão de políticas ambientais e, sobretudo, a reestruturação das funções de diferentes instituições governamentais e a consolidação de um quadro jurídico-legal, institucional e ambiental nacional.

Após a Conferência das Nações Unidas sobre o Meio Ambiente, realizada no Rio de Janeiro, no Brasil, em 1992, Cabo Verde adotou o seu primeiro instrumento legal ambiental, aprovando a Lei de Bases da Política do Ambiente - Lei N. ${ }^{\circ}$ 86/IV/93, de 26 de julho -, que fixa as grandes orientações e define o quadro legal que deve reger as relações entre o homem e o meio natural, destacando a intenção da criação de uma rede de áreas protegidas, um ano após a consagração do Direito ao Ambiente como direito fundamental na Constituição da República de Cabo Verde.

Desde aquela altura, o Estado de Cabo Verde vem ratificando as convenções internacionais ambientais por via da adesão e assinatura das mesmas, tendo em vista a integração da problemática ambiental no processo de planeamento e nas políticas de desenvolvimento relevantes para o país, de acordo com os preceitos internacionais que passam a vigorar.

No ano de 2003 as atenções estavam direcionadas para a constituição de áreas protegidas. Pelo Decreto-Lei N. ${ }^{\circ}$ 3/2003, de 24 de fevereiro, instituiu-se o Regime Jurídico das Áreas Protegidas, instrumento legal de declaração das áreas 
protegidas, recomendado pela GTZ (Cooperação Técnica Alemã para o Desenvolvimento), ${ }^{5}$ em 2002, no seu relatório sobre a Biodiversidade da Prevista Área Protegida na Ilha do Fogo/Cabo Verde, onde se propunha tomar como exemplo a classificação de diferentes categorias de áreas protegidas das ilhas Canárias, "com base nas semelhanças (característica da ilha, parcos recursos naturais e ao mesmo tempo forte dependência do homem destes recursos)" (Leyens 2002: 49).

Assim, Leyens (2002: 59) sugeriu "a adaptação dos excelentes 'Planos Rectores de Uso e Gestion' dos 'Parques Naturais' e 'Parques Rurais' das Ilhas Canárias". Para suportar este argumento nos refere que "mesmo a tendência em termos de política de proteção ambiental em Cabo Verde toma como referência o modelo das Canárias" (Leyens 2002: 50), o que nos apela à transferência de modelos do Ocidente para países do Sul.

Seguindo as orientações daquele relatório, o Decreto-Lei N. ${ }^{0}$ 3/2003, de 24 de fevereiro, estabelece o regime jurídico dos espaços naturais, paisagens, monumentos e lugares. Por esse decreto criaram-se nove parques naturais em Cabo Verde, sendo três na ilha de Santo Antão, um em São Vicente, um em São Nicolau, um no Maio, dois em Santiago e um na ilha do Fogo, para a qual se alegou a importância biológica e ecológica dos lugares a serem convertidos em parque, nomeadamente para a preservação das espécies endémicas e o potencial turístico dessas regiões, sobressaindo desse diploma a urgência de uma correta estratégia de conservação e gestão.

As ações subsequentes seguiram as orientações internacionais, nomeadamente as agendas dos financiadores, sobretudo o GEF (Fundo Global para o Ambiente) ${ }^{6}$ que financiou o Projeto de Consolidação dos Sistemas das Áreas Protegidas $^{7}$ juntamente com o PNUD (Programa das Nações Unidas para o Desenvolvimento) e a GTZ.

Cinco anos após a sua criação, o Parque Natural do Fogo foi delimitado pelo Decreto Regulamentar N. ${ }^{\circ}$ 3/2008, de 02 de junho. Segundo esse decreto, o Parque Natural do Fogo possui características biofísicas e socioculturais de grande interesse paisagístico e científico. Além dos aspetos de caráter geológico, como a extensa cratera vulcânica, a Bordeira ${ }^{8}$ e os vários cones vulcânicos, são de destacar os aspetos relacionados com a biodiversidade. Das 82 espécies de plantas endémicas de Cabo Verde, 37 surgem na ilha do Fogo e 31 delas

5 Agência alemã encarregada de executar projetos de cooperação técnica que ajudem a reduzir as discrepâncias sociais e contribuir para uma melhor proteção ao meio ambiente e para a gestão dos recursos naturais de maneira sustentável.

6 Através do Programa Estratégico para a África Ocidental, no valor de 4.183.000 USD.

7 O projeto tem por objetivo fortalecer e expandir o sistema nacional de áreas protegidas, terrestres e marinhas, visando a criação de condições para a operacionalização de quatro áreas protegidas terrestres em três ilhas diferentes (Fogo, São Vicente e Santo Antão).

8 A Bordeira se constitui como uma parede externa que circunda a caldeira, um semicírculo, podendo atingir os $1000 \mathrm{~m}$ (Ribeiro 1998). 
crescem nas zonas altas da Bordeira, cinco destas constituindo endemismos locais (Decreto Regulamentar N. ${ }^{\circ}$ 3/2008, de 02 de junho).

É de realçar que o Parque Natural do Fogo resultou de um esforço conjunto entre o governo alemão e o governo de Cabo Verde, cujas negociações para a criação do referido parque remontam a maio de 1997, posteriormente reforçadas com o estudo feito pela GTZ, o relatório sobre a Biodiversidade da Prevista Área Protegida na Ilha do Fogo/Cabo Verde (Leyens 2002).

A intervenção da Cooperação Técnica Alemã (GTZ) é justificada no relatório, pela consultora Teresa Leyens, dizendo que pretendiam "impedir a continuação da degradação dos recursos naturais causada por uma utilização exagerada e pouco diferenciada que não leva em linha de conta as capacidades de regeneração da vegetação" (Leyens 2002: 4).

Seguindo a filosofia dos primeiros parques delimitados a nível mundial, a ideia de natureza intocada, de ecossistemas pouco modificados, também está presente no relatório da GTZ. Neste particular, quando se refere às categorias de áreas protegidas, Leyens realça que "os ecossistemas a proteger são sistemas pouco modificados, utilizados pelo Homem, e que correspondem, conforme os critérios da UICN, à categoria apropriada de uma zona com utilizações múltiplas = Managed Resource Protected Area (UICN, categoria VI)" (Leyens 2002: 49, itálicos meus).

Os critérios propostos são os indicados pela International Union for Conservation of Nature (UICN), o que revela a omnipresença de organizações internacionais em todo o processo de elaboração da proposta de conservação, assim como na gestão quotidiana dos parques.

A ideia do ambiente natural pouco modificado está também presente no Terceiro Relatório Nacional sobre o Estado da Biodiversidade em Cabo Verde (DGA 2006), o qual vem contradizer as premissas das inter-relações entre os homens e o mundo natural enunciadas por Balée (1998). O modelo de parque natural adotado em Cabo Verde consistiu na não expulsão das populações do seu território.

A elaboração de um discurso político de compromisso, que leva em conta as conceções ecologistas de instituições internacionais, recorrendo a projetos de desenvolvimento durável, demonstra uma profunda incompatibilidade cultural com os caldeirenses, pois tudo é pensado numa escala internacional na qual os atores locais são os últimos a serem chamados à arena pública.

Segundo o artigo $10 .^{\circ}$ do Decreto-Lei N. ${ }^{\circ} 3 / 2003$, de 24 de fevereiro, para a declaração de uma área protegida deve ser aberto um processo de participação cívica, no qual são informadas e implicadas as populações da área envolvente e suas associações, se existirem, os municípios e as organizações não governamentais que se dedicam à proteção do ambiente.

Embora seja enunciado um interesse do Estado em assegurar a conservação dos "recursos naturais" levando em conta as necessidades das populações, para os caldeirenses a sua participação em todo o processo, culminando com 
a aprovação do Plano de Gestão do Parque Natural do Fogo, aprovado pela Resolução N. ${ }^{\circ}$ 20/2010, de 19 de abril, foi mínima. Segundo os caldeirenses, a eles somente foi apresentado o estudo que já tinha sido feito (pela GTZ) e não foram eles que deram indicações para o zoneamento, conforme se pode constatar nos enunciados seguintes:

"Não foi dada a possibilidade de participarmos. Eu não estava de acordo com o parque porque eles não tinham proposta alternativa para as pessoas daqui. A nossa situação não foi pacificada nem discutida. Eles foram pela passividade das pessoas" [D. F., 48 anos, desempregado, 2012].

"Em tudo isso fiquei com a minha boca calada. Não posso fazer nada porque a minha conversa não é ouvida” [V.P., 59 anos, agricultor, 2010].

Nesta perspetiva, segundo Li (2009), não participar de uma assembleia também é uma manifestação política, porque implica não aceitar uma realidade que não concorda com o seu "mundo vivido".

O plano vem instaurar novas regras de gestão do território, impactando as atividades agrícolas, pecuárias e extractivistas que eram desenvolvidas nesses territórios e a dinâmica ecológica e territorial, conforme se depreende dos enunciados seguintes:

"Perdi um bocado de terreno, principalmente os terrenos onde havia plantas endémicas. Se eu tenho dez filhos, um terreno está ali bonito, só para turista entrar e ver, deixar dinheiro, mas se nós não temos o que comer, como é que fica?" [V.P., 59 anos, agricultor, 2010].

"A nossa vida antes do parque era melhor, eu vivia da agricultura e da pecuária, privaram-nos e agora não temos. Na altura em que vieram mostraram-nos se aceitávamos, mostraram o lugar que iriam ocupar. Fizeram-nos essa proposta e poucos dias depois deram-nos as costas" [M. M., 25 anos, guia turístico, 2012].

Pelos enunciados nota-se que, embora haja uma tentativa de reduzir a dissonância entre diferentes visões do mundo, ficam patentes as diferenças entre os planos locais e internacionais na maneira como se pensa o desenvolvimento e o remetimento ao silêncio da visão dos caldeirenses, que traduzem outras vozes e verdades. Desta forma, os caldeirenses não puderam contestar os relatórios, as leis, todas as pesquisas que constroem uma realidade legitimada em nome do desenvolvimento.

Respondendo ao questionamento sobre o que os parques dão às pessoas, Brockington, Duffy e Igoe (2008) entendem que as vantagens e desvantagens na 
distribuição da fortuna dos parques não são consensuais e variam para diferentes grupos, exemplificando: se as mulheres perdem com a venda de medicamentos tradicionais, os jovens do sexo masculino poderão atuar como guardas florestais.

\section{COM OS ANIMAIS E AS PLANTAS: RELAÇÕES DE AFETO E RESPEITO}

Em alguns aspetos, a cosmologia caldeirense dialoga com as cosmologias anímicas amazónicas, nomeadamente no facto de os animais e plantas não estarem separados ontologicamente dos humanos. Ou seja, compartilham algumas interioridades e gozam de qualidades antropocêntricas.

No estudo de Descola (1992) sobre os achuar, povo jívaro da Amazónia equatoriana, o autor pontuou a relação entre formas de conceber e de experimentar o "mundo natural", enunciando relações sociais plenas entre os homens e o "mundo natural" por via da constatação das relações de reciprocidade e respeito que os ameríndios estabelecem com elementos como a água, os animais de caça e as plantas cultivadas.

Por sua vez, partindo de suas etnografias sobre os povos tupi, para Eduardo Viveiros de Castro (1996) plantas e animais são interlocutores legítimos; a despeito das aparências enganadoras, eles não vivem em um plano ontológico distinto daqueles dos humanos.

No caso caldeirense há indícios de que, embora não atribuam aos animais e plantas um espírito, os animais, por exemplo, além de desempenharem papéis de ajuda mútua e cooperação, desenvolvem interações sociais com os caldeirenses, no sentido das relações de afeto e respeito.

Tomando como referência esta observação, tenta-se mostrar que, de entre os atributos humanos outorgados aos burros, estes diferem dos homens pela especificidade dos corpos, a nível da morfologia corporal.

"Eles vão em cima do burro e esquecem-se que ele se cansa como eles"

[C.M., 28 anos, funcionária pública, 2012].

A interlocutora se imagina tomando a posição do animal, atribuindo ao burro uma interioridade análoga à dela, a nível da expressão da emoção, como o dom de se cansarem, permitindo o diálogo com Descola (2005).

É de realçar que os burros encontram-se vestidos em tempos quentes, facto que é explicado como proteção deles face às mordidas constantes das moscas a que são sujeitos por terem sangue doce, o que nos leva a pensar o vínculo de afeto com animais a partir das lógicas de reciprocidade.

Por outro lado, os animais interferem nas formas de viver dos caldeirenses e na maneira de se inter-relacionarem, abrindo a possibilidade de terem outra relação com o mundo por via das afinidades sentimentais, que podem ser pensadas a nível das relações com alteridades. 
A relação com o gongon (Pterodroma feae $)^{9}$ foi impactada com as normas que passaram a vigorar após a declaração de parque natural. Se antes da declaração o gongon era visto como um recurso medicinal que resolvia as dores reumáticas, com a delimitação do parque e a definição das espécies a serem protegidas pressupunha-se uma mudança de comportamentos, devido ao perigo da sua extinção, associado à sua captura pelos gatos selvagens.

"Antigamente caçávamos o gongon porque a sua banha cura muitas dores no joelho, no braço. Agora é proibido caçá-lo porque não há mais. Se o apanharmos ele vai acabar. Se nos apanharem com gongon vamos pagar multa. Se está proibido, não temos nada a fazer" [V.P., 61 anos, agricultor, 2012].

Dialogando com os estudos de Descola (1998), percebe-se que, no caso caldeirense, a morte do gongon pode ser vista como substituindo-se a uma dificuldade (doença, incômodo).

Atendendo às relações próximas que se estabelecem com as plantas, percebemos que o espaço proporciona espécies curativas como aipo branco (gripe, dores de barriga), lorna (gripe, dor de cabeça), tixerinha (dores no corpo, dor de barriga e ossos), babosa (caspa, inflamações), erva-cidreira (cólicas), erva-doce (problemas intestinais, gases), funcho (tosse), eucalipto (constipações), gestiba (tratamento da cárie dentária), arruda (tosse, mau olhado), semente de uva verde (intestino, fígado, olhos), reveladores dos vínculos existentes no domínio da natureza e de como o corpo está relacionado ao espaço.

Sergio Baptista da Silva, ao discutir a territorialidade guarani como sendo cosmo-ontológica, enfocando as relações entre corpo e território e entre natureza e cultura ou objeto e sujeito, refere que "corpos são formas fluidas, instáveis e em transformação, que necessitam de constantes esforços técnicos/rituais/sociais para que adquiram as características desejáveis e para que não sejam metamorfoseados - através das agências de alteridades perigosas em outros corpos, não Mbyá-Guarani” (Silva 2013: 51), o que nos leva à reflexão de que, no caso de Chã das Caldeiras, nas várias alteridades estão presentes essências que protegem e curam os corpos caldeirenses.

O ensinamento sobre essas plantas curativas foi passado de geração a geração. Há um processo de observação que permite reconhecer os sintomas das doenças, sejam elas de caráter natural ou sobrenatural, para assim diagnosticar

9 O gongon é uma espécie de ave marinha que nidifica nos rochedos de Chã das Caldeiras, estimando-se uma comunidade média de 250 a 300 indivíduos no perímetro do Parque Natural do Fogo, sendo considerado uma espécie endémica de Cabo Verde pela Bird Life International. O Parque Natural do Fogo tem feito o seguimento de ninhos identificados do gongon, em colaboração com a Universidade de Barcelona, desde 2007. 
o uso correto das plantas. Para além disso, o sistema curativo caldeirense, na maioria dos casos, obedece ao critério lógico de todo o sistema médico: conservação da saúde, prevenção das doenças e restituição da saúde.

Os caldeirenses também estendem a cura proporcionada pelas plantas, especialmente as endémicas, aos animais:

"Qualquer dessas plantas endémicas dá aos animais mais força, mais leite" [C. V., 49 anos, agricultor e produtor de vinho, 2012].

"A mamona e piorno quando estão verdes, há época que não deve ser apanhada porque é forte, pode matar as cabras. Temos que deixar amarelar para ganharem força e aí poderemos lhes dar. Mas já não há pasto. Não há o que apanhar" [V.P., 61 anos, agricultor, 2012].

Os caldeirenses detêm grande conhecimento das plantas e dos cuidados para evitar doenças, pelo que vigiam que as cabras não comam as plantas que podem provocar a sua morte, revelando cuidado e proteção para com os animais.

"Vejo os animais como a nós mesmos, para os alimentar a toda a hora, para não serem mordidos pelas moscas, para estarem protegidos, para não serem maltratados nem atacados por outros animais ou por nós mesmos" [C.M., 28 anos, funcionária pública, 2012].

"Todos os animais têm o seu respeito" [V.P., 61 anos, agricultor, 2012].

As relações de proteção e afeto para com os animais também se verificam entre o vulcão e os animais, onde aquele dá-lhes tempo para se protegerem na altura das erupções.

"O vulcão anda lentamente. Se a pessoa quiser fugir ela pode. Nem um animal sofre" [L.M., 62 anos, agricultor, 2012].

Ribeiro (1998), na sua monografia geográfica da ilha do Fogo, onde descreveu as erupções que ali tiveram lugar, principalmente a de 1951, constatou que nenhum animal perde a vida nas erupções.

\section{A DINÂMICA RELACIONAL DOS CALDEIRENSES COM O VULCÃO: IRMÃO, AMIGO, GENEROSO, MÁGICO, FIEL, CONFIÁVEL}

Consta na cosmologia caldeirense que o vulcão os deixou morar em Chã das Caldeiras, sendo uma dádiva deste para os caldeirenses. 
"Nós e o vulcão olhámo-nos uns aos outros, ele não nos empurrou e nem nós o empurrámos. Ele não correu connosco" [M.M., 81 anos, agricultor, $2012]$.

Há indícios de uma convivência de entendimento e proteção entre os caldeirenses e o vulcão, ou seja, cuidam-se mutuamente. Para os caldeirenses, o vulcão é considerado possuidor de subjetividade, atributos da humanidade, com capacidade de se perceber a si mesmo e ao seu comportamento sob a forma de cultura.

Além disso, dialogando com Deleuze e Guattari (1980), o território se entreabre para o amigo, como se depreende dos enunciados seguintes:

“O meu pai estimava o vulcão como se fosse seu amigo, seu irmão. Viemos aqui e o encontrámos, é o nosso irmão mais velho, que ao nascer encontramos" [C.M., 28 anos, funcionária pública, 2012].

"Nós ficámos amigos do vulcão porque não sentimos receios dele" [M. M., 81 anos, agricultor, 2012].

Para além de o vulcão ser comparado a um amigo, ele também é tratado como um parente próximo, quando comparado a um irmão mais velho. Daí que poderemos sugerir que o vulcão, sendo um irmão do caldeirense, também é caldeirense. São atribuídas ao vulcão qualidades antropocêntricas e sociais, funcionando em regimes próximos de sociabilidade com os humanos, daí as semelhanças ao animismo enunciado por Descola (1992). ${ }^{10}$

A relação com esse amigo é de fidelidade, respeito, nela há confiança mútua, e essa relação proporciona felicidade.

“Temos confiança imensa que ele não nos faz mal, as pessoas aqui estão felizes todas as vezes que o Sol se levanta atrás do vulcão" [C.M., 27 anos, funcionária pública, 2012].

Quando há todo um discurso técnico-científico que considera a região de Chã das Caldeiras como sendo de risco vulcânico, por ser uma zona com maiores probabilidades de ocorrência de erupções, ${ }^{11}$ para os caldeirenses esta questão não se coloca porque o vulcão é um amigo, que com eles comunica.

10 O animismo objetiva a natureza em que plantas e animais possuem status de pessoa, uma vez que são portadores de qualidades antropocêntricas e sociais. Está fundado na homologia de interioridades e numa diferença de materialidades (Descola 2005).

11 Autores como Bebiano (1932) ou Friedlaender (1914) defendem que toda a ilha do Fogo constitui um enorme cone vulcânico, podendo ocorrer erupções em qualquer lugar da ilha. 
"Não tenho medo do vulcão porque nós corremos risco em qualquer lugar do mundo. Eu o encaro e vejo como algo normal. Onde estiveres não estarás seguro" [M.M., 25 anos, empresário, 2012].

"Eu acho que aqui não existe perigo" [A.M., 16 anos, estudante, 2013].

Viver debaixo do vulcão não seria assombroso entre os caldeirenses, pois viver no mundo é assombroso, o perigo é a vida, é ser um ser errante, desadaptado. Tais relatos permitem desestabilizar modelos teóricos dominantes que se consideram superiores à perspetiva e visões do mundo das populações locais.

"Não posso ter receios dele porque sou mais complicado do que ele. Por dia expludo três a quatro vezes e ele é de muito em muito tempo, eu estou constantemente a explodir. Se vieres me medir a temperatura com um termómetro e o vulcão com os aparelhos verás que ele tem a sua temperatura e eu a minha" [M.M., 81 anos, agricultor, 2012].

Assim como os humanos utilizam o termómetro para medir a temperatura, os sismógrafos também avaliam a temperatura do vulcão. Embora os corpos sejam diferentes, ambos têm uma temperatura. Contudo, o último entrevistado revela que ele é mais complicado de que o vulcão, que num dia explode várias vezes, ao contrário do amigo (vulcão), que é mais paciente, que demora a explodir.

Deste modo, a personalidade do caldeirense é comparada à do vulcão, quando se refere ao seu estado de espírito. Por exemplo, numa conversa informal, uma das minhas interlocutoras me disse que alguém lhe tinha referido, numa situação específica: "és pequena mas tens raiva como esse vulcão" [F.M., 36 anos, agricultora, 2012]. Por esse enunciado, fica assente que o vulcão tem raiva, não é somente amigo, ao mesmo tempo é inimigo.

Neste particular, se atendermos à erupção de 1995, o governo de Cabo Verde, apoiado pela Cooperação Técnica Alemã, com o objetivo de pôr termo aos povoados de Chã das Caldeiras, adotou um plano de emergência para o realojamento da sua população em áreas residenciais consideradas de menos risco, em Achada Furna e Monte Grande, com a construção de 114 casas. Contudo, qualquer tentativa de reuni-los em outras zonas fracassou. Rejeitando a desertificação de Chã, os caldeirenses voltaram para ali por não quererem se desfazer dos terrenos férteis que, diariamente, lhes garantem a sua subsistência, para além da grande amizade com o amigo vulcão:

"Em 95, todos os dias de manhã eu vinha de Mosteiros para aqui, porque lá em Mosteiros é quente, não estávamos acostumados com a comida dali” [C. V., 49 anos, agricultor e produtor de vinho, 2012]. 
"Em São Filipe os nossos filhos castigaram-se com fome, escola, eles não conheciam a região. Vieram a dar-nos casa, colocaram telha que não era boa. Voltámos porque não sentimos bem ali" [A.T., 92 anos, pensionista, 2013].

Para além de não haver território suficiente para a prática da agricultura e para a pecuária, por esses enunciados nota-se o facto de não se acostumarem em Mosteiros porque ali é quente, o que nos leva a questionar como o corpo está relacionado com o espaço de Chã das Caldeiras. Esse corpo é fabricado, criado para viver em Chã, para comunicar com o vulcão, ouvir os sons transmitidos pelo vulcão, cheirar o aroma do enxofre, provar o sabor "forte" dos alimentos que germinam no local.

Questionava durante o trabalho de campo o que significava o calor, fogo, quentura, que eram categorias utilizadas pelos caldeirenses para se referirem ao vulcão. Percebia que, assim como é enunciada a fertilidade do terreno, ela também é referenciada entre os caldeirenses pelo facto de cada família possuir uma grande prole. A fertilidade é associada ao vulcão, que emana forças, chamas, influenciando os caldeirenses homens a terem várias parceiras e filhos, pois todos têm fogo. É esse calor que faz com que as mulheres tenham marido/companheiro cedo.

“Temos quentura do vulcão. Todas as pessoas da Chã têm ponto quente, ou na tensão, ou a falar (falam alto, alterado), ou a arranjar mulher, marido cedo. Todas as pessoas têm fogo. Aqui gostamos mais porque estamos mais próximos do vulcão. Vulcão é fértil em todas as áreas: terreno é fértil derivado do vulcão, as pessoas da Chã são férteis, têm muitos filhos. É fértil porque alimentamos da comida que alimenta da terra do vulcão. Não é somente nós, todas as pessoas vêm aqui alimentar e levam aquele fogo. A comida tem força do vulcão" [C.M., 29 anos, funcionária pública, 2013].

Nota-se que as características do "vulcão" são incorporadas pelos caldeirenses (explosão, quente, fogo).

Os caldeirenses fazem a analogia do vulcão a um ser vivo que interpenetra o mundo social e com ele comunica:

"Vulcão é um ser vivo como eu. Sempre que ele vai entrar em erupção ele comunica. Quando vou fazer necessidade sinto que estou pronto para ir, ele também quando vai entrar em erupção nos avisa, um mês antes, nunca é de repente, dá-nos tempo para sairmos" [M.M., 25 anos, guia turístico, 2012].

Segundo esse enunciado, a erupção vulcânica é comparada à necessidade fisiológica. Contudo, diferente do que acontece entre os humanos, em que tal necessidade não precisa ser comunicada aos demais, o vulcão quando tem essa 
necessidade comunica-a aos caldeirenses. Exemplo semelhante ocorre quando outro interlocutor me diz que o vulcão tem vida e que quando estiver com o estômago cheio necessita de vomitar.

Por outro lado, não apenas o vulcão pode falar, como os caldeirenses são capazes de entender a sua linguagem, o que ele quer transmitir, demonstrando a grande e intensa comunicação entre esses seres que possuem pontos de vista, subjetividade e agência uns sobre os outros, permitindo o diálogo com as pesquisas de Descola (2005) sobre os povos ameríndios.

A relação de amizade com o "vulcão" é explicada através da comunicação, voluntária e involuntária, que se mantém diariamente e mais intensamente na altura das erupções, atribuindo-lhe características humanas, como o bater à porta, andar, caminhar, demonstrando que o vulcão não lhes faz mal, como se pode exemplificar no seguinte enunciado:

"No dia da erupção ele nos bate à porta, faz-me movimentar, nós ficamos a saber que ele vai explodir, só que não sabemos onde. No movimento e sacudidela, a porta fica a bater, ele nos bate à porta. Quando ele começa a sua atividade, a primeira coisa, ele sacode duas a três vezes por dia, depois são dezenas de vezes de uma vez quando ele fura. Eu o conheço mais do que vulcanólogos. Quando ele furar nós vemos seu movimento como casamento, porque vamos sem ter dúvidas nele, ele entra, mas nós não o consideramos inimigo porque não temos condições" [M.M., 81 anos, agricultor, 2012].

O interlocutor destaca que detém conhecimento que ultrapassa o dos vulcanólogos. O vulcão é assim concebido como um ser vivente, uma conceção na qual não há uma separação estrita entre humanos e natureza.

Neste caso, o vulcão possui qualidades de pessoa - de uma pessoa dotada de alma, o que lhe permite comunicar com os caldeirenses. Neste sentido, o que distingue o vulcão dos caldeirenses não são as interioridades e sim as materialidades. Ou seja, perante uma diferença de corpos, temos uma identidade de almas. O vulcão compõe os corpos e as pessoas caldeirenses, o que permite dialogar com a noção melanésia de "divíduo" descrita por Strathern (1988), que nos diz que as pessoas são frequentemente construídas como o lócus plural e compósito das relações que as produzem. Tal conceito é útil no sentido em que nos leva a refletir sobre a construção de pessoa.

Desta forma, o vulcão pode ser considerado um "divíduo", constituído por relações plurais. O que quer dizer que o vulcão é uma pessoa que não é considerada em si mesma ou por si mesma, mas que está dispersa na expansão das relações sociais. Esse corpo é composto pelas suas relações, que podem ser dadas aos caldeirenses na forma de comunicação, "batimento na porta”, sonhos. Daí que a dualidade, singular-plural, esteja em constante 
movimento de um estado para outro, que se materialize na capacidade reflexiva.

O sujeito caldeirense implica em uma singularidade permanente dividida entre "eu" e "outro", em que o outro está contido no próprio sujeito, ou seja, na alma.

O corpo também é parte constitutiva do "divíduo", aqui entendido na perspetiva de Viveiros de Castro (2002), não no sentido biológico, mas sim enquanto série de afeções. Como afirma Bennett (2010), os corpos nunca agem sozinhos e um evento nunca é determinado apenas pelas intenções de um único corpo. Isto sugere que o reconhecimento de que não somente os humanos agenciam pode trazer mais responsabilidade política, ou seja, uma política menos dedicada a culpar e condenar indivíduos e mais a discernir a teia de forças que afetam situações.

Para além disso, a aliança dos caldeirenses com o amigo vulcão é reforçada pelo facto de este fazer com que a lava corra devagar, fazendo o cálculo de modo a não os prejudicar, segundo enunciados caldeirenses:

"Quando vai entrar em erupção ele nos avisa, as lavas correm devagar. Não nos prejudica em nada, sempre ele escolhe lugar para furar, ele não chega em nós" [C. M., 28 anos, funcionária pública, 2012].

"Vulcão corre devagar como onda de mar, ele calcula, ele embarca" [A. T., 92 anos, pensionista, 2012].

Ao vulcão são atribuídas não somente disposições antropocêntricas (o dom de comunicar com os humanos), como também atributos sociais. É ainda assegurada a consciência reflexiva e a intencionalidade; capaz de expressar emoções, é incluído entre as "pessoas", comunicando com elas através do envio de mensagens.

Por outro lado, tendo em conta as relações com o vulcão, reveladoras das especificidades locais e imprescindíveis para os dispositivos legais e a gestão do parque, seguindo a proposta de Blaser (2010) há que repensar o mundo como "mundos de relações", em vez de realidades preestabelecidas e, a partir disso, repensar o "político".

Daí a inclusão da atitude cosmopolítica, ou seja, “a possibilidade de se criar um espaço de hesitação, de se desacelerar a expectativa pela construção de um mundo comum, ao se sugerir que 'talvez possa existir algo de mais importante" " (Stengers 2007: 49).

Após alguns questionamentos que surgiram na minha reflexão sobre a etnologia caldeirense, destacava: o que é o vulcão para os caldeirenses? Seria um amigo ou um inimigo ao mesmo tempo? Um consanguíneo ou um afim? Um ser? Uma entidade? Um Deus? Uma propriedade imaterial? Entendo que, 
diferentemente dos sentidos usuais que lhe são atribuídos pelos técnicos, pelos enunciados caldeirenses é possível sugerir que o vulcão seja uma multiplicidade de diferenças.

\section{CONCLUSÕES}

A pesquisa etnográfica realizada em Chã das Caldeiras evidenciou tensões entre cosmo-ontologias diferentes (as caldeirenses e as ocidentais que fundamentam a implementação de parques naturais), porque no processo de delimitação do Parque Natural do Fogo não foram consideradas as relações entre diferentes lógicas sociais e ecológicas.

$\mathrm{Na}$ cosmologia caldeirense, distinções como plantas, vulcão, humanos, animais não se verificam, ou seja, não existe sociedade e natureza de forma distinta, mas, pelo contrário, há indícios de partilha de qualidades antropocêntricas e sociais com outros seres do cosmos, atribuindo sentido aos diversos elementos constitutivos do meio ecológico. Há um grande respeito pela existência do outro, ou seja, pela alteridade, em relação ao vulcão, às plantas, aos animais, à terra, à Bordeira.

É a dimensão da interação entre natureza e cultura que precisa ser adotada pela política ambiental cabo-verdiana, que está relacionada à dimensão eurorreferenciada, num processo de simetrização, colocando em igualdade as vozes políticas. Ou seja, é preciso reconhecer as alteridades e fazer com que essas cosmologias outras afetem as pretensões epistemológicas do Ocidente, sob pena de as políticas adotadas estarem destinadas ao insucesso. 


\section{BIBLIOGRAFIA}

BALÉE, William, 1998, "Historical ecology: premises and postulates”, em William Balée (org.), Advances in Historical Ecology. Nova Iorque, Columbia University Press, 13-29.

BEBIANO, José Bacelar, 1932, A Geologia do Arquipélago de Cabo Verde. Lisboa, Oficina Gráfica. BENNETT, Jane, 2010, Vibrant Matter: A Political Ecology of Things. Durham, Duke University Press.

BLASER, Mario, 2010, Storytelling Globalization from de Chaco and Beyond. Durham, Duke University Press.

BROCKINGTON, Dan, Rosaleen DUFFY, e Jim IGOE, 2008, Nature Unbound: Conservation, Capitalism and the Future of Protected Areas. Londres, UK, e Sterling, VA, Earthscan.

CASTRO, Eduardo Viveiros de, 1996, "Os pronomes cosmológicos e o perspectivismo ameríndios", Mana, 2 (2): 115-144.

CASTro, Eduardo Viveiros de, 2002, A Inconstância da Alma Selvagem e Outros Ensaios de Antropologia. São Paulo, Cosac Naify.

COSTA, F. Lagos, 1997, "Indicadores geormofológicos de risco vulcânico na Chã das Caldeiras (ilha do Fogo, Cabo Verde)”, A Erupção Vulcânica de 1995 na Ilha do Fogo, Cabo Verde. Lisboa, Instituto de Investigação Científica Tropical, 235-256.

DARBOn, Dominique (org.), 1999, La Politique des Modèles en Afrique: Simulation, Dépolitisation et Appropriation. Paris: Karthala-MSHA.

DELEUZE, Gilles, e Félix GUATTARI, 1980, Mille Plateaux. Paris, Minuit.

DESCOLA, Philippe, 1992, "Societies of nature and the nature of society", em A. KUPER (org.), Conceptualizing Society. Londres, Routledge, 107-126.

DESCOLA, Philippe, 1998, "Estrutura ou sentimento: a relação com o animal na Amazônia", Mana, 4 (1): 23-45.

DESCOLA, Philippe, 2005, "Más allá de la naturaleza y la cultura”, Etnografías Contemporáneas, 1 ( 1 ), 93-114.

DGA - DIREÇÃO-GERAL DO AMBIENTE, 2006, Terceiro Relatório Nacional sobre o Estado da Biodiversidade em Cabo Verde. Praia, Direção-Geral do Ambiente.

FRIEDLAENDER, Immanuel, 1914, Subsídios para o Conhecimento das Ilhas de Cabo Verde: Resultados de Uma Viagem de Estudo no Verão de 1912. Lisboa, Tipografia de Cooperativa Militar, trad. A. J. Garcia Guerreiro.

LATOUR, Bruno, 1994, Jamais Fomos Modernos: Ensaio de Antropologia Simétrica. Rio de Janeiro, Editora 34, trad. Carlos Irineu da Costa.

LEYENS, Teresa, 2002, Biodiversidade da Prevista Área Protegida na Ilha do Fogo/Cabo Verde: Elaboração de Programas e Medidas para a Sua Conservação Sustentável. Eschborn (RFA), GTZ.

LI, F., 2009, "Documenting accountability: environmental impact assessment in a Peruvian mining project", Political and Legal Anthropology, 32 (2): 218-236.

RIBEIRO, Orlando, 1998, A Ilha do Fogo e as Suas Erupções. Lisboa, Comissão Nacional para as Comemorações dos Descobrimentos Portugueses.

SILVA, Sergio Baptista da, 2013, “Cosmo-ontológica mbyá-guarani: discutindo o estatuto de 'objetos' e 'recursos naturais'”, Revista de Arqueologia, 26 (1): 42-54.

STENGERS, Isabelle, 2007, "La proposition cosmopolitique", em Jaacques Lolive e Olivier Soubeyran, L'Emergence des cosmopolitiques. Paris, La Découverte, 45-68.

STRATHERn, Marilyn, 1988, The Gender of the Gift: Problems with Women and Problems with Society in Melanesia. Berkeley, University of California Press. 